\title{
Article \\ Gender Differences in Repeated Dishonest Behavior: Experimental Evidence
}

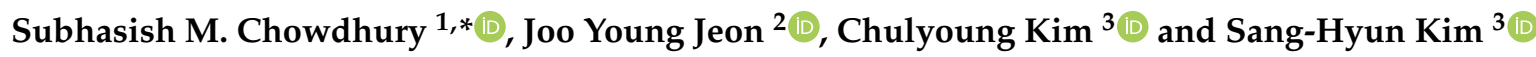 \\ 1 Department of Economics, University of Bath, Bath BA2 7AY, UK \\ 2 Department of Economics, University of Reading, Reading RG6 3AA, UK; j.jeon@reading.ac.uk \\ 3 School of Economics, Yonsei University, Seoul 03722, Korea; chulyoung.kim@yonsei.ac.kr (C.K.); \\ sang.kim@yonsei.ac.kr (S.-H.K.) \\ * Correspondence: s.m.chowdhury@bath.ac.uk
}

Citation: Chowdhury, S.M.; Jeon, J.Y.; Kim, C.; Kim, S.-H. Gender

Differences in Repeated Dishonest

Behavior: Experimental Evidence.

Games 2021, 12, 44. https:/ /doi.org/

$10.3390 / g 12020044$

Academic Editors: Rainer

Michael Rilke, Stefania Bortolotti and Ulrich Berger

Received: 29 January 2021

Accepted: 17 May 2021

Published: 21 May 2021

Publisher's Note: MDPI stays neutral with regard to jurisdictional claims in published maps and institutional affiliations.

Copyright: (c) 2021 by the authors. Licensee MDPI, Basel, Switzerland. This article is an open access article distributed under the terms and conditions of the Creative Commons Attribution (CC BY) license (https:/ / creativecommons.org/licenses/by/ $4.0 /)$.

\begin{abstract}
We investigate gender differences in lying behavior when the opportunity to tell lies is repeated. In specific, we distinguish the situations in which such an opportunity can be planned versus when it comes as a surprise. We utilize data from an existing published research and show that when the opportunity to tell a lie comes as a surprise, then on the first occasion, males lie more than females. However, when telling lies can be planned, then there is no gender difference in telling a lie. When planning is possible, females tell more lies in the first occasion compared to when it is not possible to plan; males do not show such behavior. On the second and final occasion, males tell more lies than females when they either could not plan but had the opportunity to a lie before, or could plan but did not have to tell a lie before. These observations can be interpreted in terms of the gender differences in consistent versus compensatory moral behavior.
\end{abstract}

Keywords: dishonesty; lying; pre-planning; gender; experiment

\section{Introduction}

Dishonest behavior has always been an active research area in philosophy, psychology, and economics. Behavioral economists extensively investigated dishonesty, and in specific the behavior of telling lies. Numerous theoretical studies (e.g., Cartwright and Menezes [1]), surveys (e.g., Bucciol et al. [2]), laboratory experiments (e.g., Fischbacher and FöllmiHeusi [3]), field experiments (e.g., Azar et al. [4]), and neuroscience experiments (e.g., Garett et al. [5]) have been carried out to understand lying behavior. Overall, various socioeconomic factors such as demographic variables, norm, context, bias, etc. turn out to be significant predictors for telling lies. However, the effects of one of the main demographic factors, gender, remains debated. Although the data from various surveys and metaanalyses show that males tell lies more than females, this difference depends heavily on the background, context, stake size, and task. Neuroscience studies also show mixed results. Studies such as Marchewka et al. [6], asking subjects to tell lies, find gender differences. However, Zhang et al. [7] could not find such a result when eliciting lying behavior.

Jacobsen et al. [8] surveyed the literature on dishonesty with more than 100 studies from economics, psychology, and management. They concluded that dishonesty is sensitive to various behavioral components such as decision contexts, reciprocity, state of the mind, etc. Abeler et al. [9] used data from 90 experimental studies and ran their own experiments to understand the motives behind telling lies. One of the results that stood out from these studies and the meta-analysis by Rosenbaum et al. [10] is that overall females are less dishonest than males.

A majority of the individual studies with various frames such as theft [11], acquiring undeserved payment [4], self-reported outcome [12,13], group-setting [14], etc. find females to tell fewer lies. Dreber and Johannesson [15] also observed the same in a sender-receiver game. However, Gylfason et al. [16] replicated that design and could not find such an 
effect. Childs [17] also found no gender difference in that game for high stake decisions. Gino et al. [18] showed that when females lag behind in a math-based competition, then they use more deception. Similarly, Gino and Pierce [19] found that there is no gender difference in dishonest behavior when it is aimed at reducing (perceived unfair) inequality. Holm and Kawagoe [20] illustrated no gender effect in lying in case of face-to-face interaction.

Hence, whereas there is a large existing body of literature documenting gender differences in lying behavior, the broad conclusion still remains incomplete. Therefore, further research is needed on the context and structure for which such gender differences can be obtained. Moreover, in real life the opportunity to tell lies is often repeated. Whereas there are studies that consider lying behavior in repeated settings (e.g., Rilke et al. [21], and Belot and van de Ven [22]), no research investigated gender difference in such a situation. We focus precisely on the gender differences in repeated lying and fill in that gap in the literature. Specifically, we study (i) whether there is a gender difference when the opportunity to tell lies occurs repeatedly; and (ii) whether there is a gender difference when such opportunities to tell lies can be planned versus when it cannot.

We use the data from an experimental study by Chowdhury et al. [23], in which subjects make two consecutive decisions. Each time they may have an opportunity to tell a lie that gives a higher payoff than telling the truth. Depending on the treatment, either they are aware of the two tasks beforehand and can pre-plan their lies, or they learn about the individual task in each stage and cannot make such a plan. The aim of Chowdhury et al. [23] was to understand the effects of the opportunity to pre-plan on dishonest behavior. The results show that when subjects are able to pre-plan, overall they lie more in the first task. On the other hand, when they cannot pre-plan, they tell lies more in the second task only when they had a chance to tell a lie earlier. However, since gender effect was not the aim, Chowdhury et al. [23] did not go beyond controlling for gender in the regressions, and the only relevant result that can be obtained from that study is that males tell more lies in the second task.

We investigate the data further and analyze the gender-specific effects. We find that when the subjects could not pre-plan, then in the first task males tell lies more than females. However, when it can be pre-planned, then there is no such gender difference. This is because females tell more lies when they can pre-plan, but males do not do so. In the second task, males tell lies more when they could pre-plan but did not get the opportunity to tell lies earlier, or when they could not pre-plan but had such opportunity earlier. Hence, it seems that males and females follow different paths of moral cleansing and behavioral spillover when planning is possible. These results contribute to the divided literature on the gender difference in lying; and show that context, earlier experience, and the possibilities to pre-plan can explain overall gender differences in dishonest behavior.

\section{Experimental Design}

Chowdhury et al. [23] designed a two-stage individual decision-making experiment with two tasks to understand dishonest behavior, where the subjects could either plan beforehand to tell a lie in each task or not according to the treatment. The experiment is described as follows: "In each stage, a subject observed a picture of a coin. Observing the picture of the coin, subjects completed a sentence "___ side is up" by choosing 'Head' or 'Tail.' Regardless of whether the head or the tail appeared on the screen, in each stage, the subject could earn more money if he/she reported 'Head' instead of reporting 'Tail'". The instructions are in the Appendix A.

In either stage, the subjects did not know what picture they will observe. By treatment design, in the first stage, half of the subjects observed 'Head' $(\mathrm{H})$ and the other half observed 'Tail' (T); and all the subjects observed 'Tail' in the second stage. Note from the instructions, the subjects were informed that they will either observe the 'Head' or the 'Tail' side of the coin. However, only the 'Tail' side was shown in the second stage. While this is providing with only partial information, this is not 'deception' as one of the two stated choices, and not something else, was indeed shown. 
In either stage, a subject observing a 'Tail' would have to tell a lie and report 'Head', in case they intend to obtain the higher payoff; but a subject observing 'Head' would not have to do so. Thus, the theoretical prediction, irrespective of the level of incentives, is to tell a lie whenever the opportunity arises. In specific, in the first stage a subject earned $5000 \mathrm{KRW}$ (South Korean Won) by reporting 'Head', and 0 KRW by reporting 'Tail'. In the second stage, a subject earned $2000 \mathrm{KRW}$ by reporting 'Head', and $1000 \mathrm{KRW}$ by reporting 'Tail'. The aim of Chowdhury et al. [23] was also to "examine whether a subject becomes more vulnerable to even a smaller monetary temptation once he/she has given in (or got succumbed) to a larger temptation". This is why they included a design with different payoffs in different stages. This could bring in issues in treatment effects in planning. Note, however, that in the current study we aim at 'treatment effect' in gender. All the subjects of both genders face the same design and same payoff structure. Hence, the payoff structure does not affect the results in the current study.

Furthermore, in two different treatments, the information structure was either 'Myopic' (M), i.e., the subjects were given the instructions of only the imminent task before each stage began; or it was 'Planned' $(\mathrm{P})$ in which the subjects were given the description of the whole experiment (about both the stages) at the beginning. As a result, subjects in the planned treatments could make an integrated plan for their action in each stage beforehand, but subjects in the Myopic treatment could not do so.

Hence, there were a total of four treatments in which subjects were: (1) myopic and observed Head in stage 1 or MH; (2) myopic and observed Tail in stage 1 or MT; (3) planned and observed Head in stage 1 or PH; and (4) planned and observed Tail in stage 1 or PT. Although the experiment had evenly distributed subjects in terms of gender (46.4\% female), Chowdhury et al. [23] did not focus on any gender effect. Table 1 shows the gender distribution by treatment.

Table 1. Subject distribution by treatment and gender.

\begin{tabular}{ccccc}
\hline Treatments & MH & MT & PH & PT \\
\hline Female & 24 & 21 & 24 & 21 \\
Male & 22 & 28 & 25 & 29 \\
\hline Total & 46 & 49 & 49 & 50 \\
\hline
\end{tabular}

Observe that being able to plan may make subjects to follow consistent (behavioral spillover as in Garrett et al. [5]) or compensatory (moral cleansing and moral licensing as in Gneezy et al. [24]) behavior. Behavioral spillover construes behaving consistently in repeated decision making, and hence a subject behaving honestly (dishonestly) should be repeating such action in repeated opportunities. Moral cleansing, on the other hand, is described as a current behavior that allows regaining moral self-worth given a past immoral behavior. Similarly, moral licensing is a current moral behavior to earn license to behave immorally in the future. Hence, these two are essentially 'compensatory' behavior that reverses the action from one to another opportunity. Chowdhury et al. [23] found that being able to pre-plan made subjects tell more lies in the first stage. Moreover, behavioral spillover persisted among myopic subjects, i.e., they told more lies in the second stage if they had an opportunity to tell lies in the first stage.

The computerized between-subject experiment was run at Yonsei University, South Korea, through Google survey. Yonsei University Ethics Approval (7001988-201808-HR220-06) was obtained for this project. The subjects were South Korean students at Yonsei University recruited by email. They had not participated in any economics experiment before. A post-experiment survey was run to collect the demographic information (age, gender, religion, and college within the university) of the subjects. However, since about $40 \%$ of the subjects did not fill in the information for religion and college, those two variables were later dropped. Each session took about half an hour, and the average payment was KRW 8685 (about 8 USD). 


\section{Results}

\subsection{Gender Differences in Stage 1}

Recall that the subjects who observed Head in the first stage (treatments $\mathrm{MH}$ and $\mathrm{PH}$ ) did not have to tell a lie to earn a higher payoff. Indeed, none told a lie in the first stage in these two treatments. Hence, we focus on treatments MT and PT and the corresponding behavior across gender. Table 2 reports the numbers and proportion of subjects telling a lie in MT and PT, separated by gender.

Table 2. Number (Proportion) of subjects lying in the first stage.

\begin{tabular}{ccccc}
\hline Treatment & MT & PT & MT + PT & Total \\
\hline Female & $9(0.429)$ & $17(0.810)$ & $26(0.619)$ & $26(0.289)$ \\
Male & $20(0.714)$ & $22(0.759)$ & $42(0.737)$ & $42(0.404)$ \\
\hline Total & $29(0.592)$ & $39(0.78)$ & $68(0.687)$ & $68(0.351)$ \\
\hline
\end{tabular}

The numbers indicate the following: 9 out of 21 (i.e., $42.9 \%$ ) females in MT and 17 out of 21 (i.e., 81\%) females in PT told lies in the first stage. Overall, 26 out of 90 (i.e., 28.9\%) of all females told lies in the first stage (because 0 females told lies both in $\mathrm{MH}$ and $\mathrm{PH}$ ) and so on. The last row of Table 2 reaffirms the result from Chowdhury et al. [23] that overall subjects who can plan for both stages (PT) tell lies more than their myopic counterparts (MT). Note, though, that this overall treatment effect is driven by the difference in behavior by females. Whereas only $42.9 \%$ of myopic females tell a lie, $81 \%$ of females who can pre-plan do so. Compared to this, $71.4 \%$ of myopic males and $75.9 \%$ of males who can pre-plan tell a lie. To test the significance of this observation, we ran the LR chi-square test with the $2 \times 2$ contingency table. It shows that there is no significant difference in males telling a lie across treatments $(p=0.704)$, but more females tell a lie in PT than in MT $(p=0.010)$. For each Chi-sq test we also ran the Fisher's exact test, and the results remain the same. This gives our first result.

Result 1 (within gender). In the first stage, the opportunity to pre-plan does not affect male lying behavior; but such an opportunity significantly increases the proportion of females lying.

Note from the last column of Table 2 that across treatments, overall, a greater proportion of males $(40.4 \%)$ tell a lie compared to their female counterparts $(28.9 \%)$. This is a relatively frequent result observed in the literature, especially on experiments requiring self-reports. However, looking closer, there is a strong difference in such behavior in terms of the opportunity to pre-plan. When all the subjects are myopic (MT), then the males tell more lies $(71.4 \%)$ compared to the females $(42.9 \%)$. However, this result seems to not hold when both males and females can pre-plan (PT). To test this, we again run LR chi-square tests. Indeed, it turns out that in MT, there is a significant gender difference $(p=0.043)$; but with the opportunity to pre-plan, there is no significant difference in the proportion of male and females lying $(p=0.666)$. This is summarized below.

Result 2 (between gender). When telling lies cannot be pre-planned, then males tell lies more than females in the first stage. However, when it can be pre-planned, then there is no gender difference in telling lies.

We then run a probit regression in which the dependent variable takes the value 1 if the subject told a lie, and 0 otherwise. The explanatory variables are the treatment dummy (whether pre-planning was possible), a dummy for female subjects, the interaction between the two dummies, and the age of the subject. Since interactions in nonlinear models are difficult to interpret, in a second regression we also report a linear probability model with heteroscedasticity robust standard errors. Supporting the non-parametric results, in both the regression models the treatment dummy is not significant, female dummy is negative and significant, whereas the interaction is positive and significant. The coefficients of these regressions are reported in Table 3. 
Table 3. Probit regression: Lying in the first stage.

\begin{tabular}{ccc}
\hline Lying in the First Stage & Probit Model & Linear Probability Model \\
\hline Planned $=1$ & 0.160 & 0.055 \\
& $(0.360)$ & $(0.123)$ \\
Female $=1$ & $-0.825^{* *}$ & $-0.310^{* *}$ \\
& $(0.393)$ & $(0.141)$ \\
Planned $=1$ *Female $=1$ & $0.959^{*}$ & $0.346^{*}$ \\
Age & $(0.555)$ & $(0.184)$ \\
& -0.038 & -0.013 \\
Constant & $(0.057)$ & $(0.019)$ \\
& 1.500 & $1.026^{* *}$ \\
\end{tabular}

Number of observations

99

99

Note. ${ }^{*}$, and ${ }^{* *}$ denote significance at $10 \%$, and $5 \%$ level. The dependent variable takes the value 1 if the subject lied in the first stage, and 0 otherwise. 'Planned $=1$ ' is a dummy variable that takes value the 1 for $P$ treatment and 0 for M treatment; 'Female $=1$ ' is a dummy variable for females. The linear probability model includes robust standard error.

Both Result 1 and Result 2 are new to the literature and are of interest for two reasons. First, no existing study investigated gender differences in telling repeated lies. These results imply that when the opportunity to tell a lie comes as a surprise, then in the first instance, males tell lies more than females; but this gender difference does not persist when telling lies can be pre-planned. Since males do not change their behavior, but females tell more lies in case of pre-planning, overall dishonest behavior on the outset also increases.

The existing literature reports that females resort to dishonesty more when they are reminded that they can do so [25], or they can make an excuse to do so [12], but that is not the case for males. In specific, Fosgaard et al. [25] show that increasing the 'awareness of cheating' (either showing explicitly in the report sheet in the experiment that cheating is an option, or that peers are dishonest) makes females cheat more. Similarly, Ward and Beck [12] ran an experiment to test whether societal obligations stop females from cheating, and whether preparing an excuse can relax such obligations for females. They found that indeed when the females could make excuses, they cheated more. Note also that in our instructions, we explicitly ask participants to think about what they would report if either 'Head' or 'Tail' comes up. This constitutes a reminder to pre-plan, and it can trigger both 'awareness' as well as 'planning for excuse' on females, producing our result. Hence, when females can pre-plan, and pre-planning works similar to a reminder (that cheating is possible) or it prepares the females to make excuses for the immediate task, then it can explain Result 1 and Result 2.

\subsection{Gender Differences in Stage 2}

Next, we focus on the lying behavior in the second stage. This is important to observe because the ability to pre-plan can trigger a moral cleansing effect on the subjects [23], but this effect may be different across gender. In Table 4, we report the proportion of subjects telling lies in the second stage for each treatment separated by gender. Similar to the majority of the literature, males overall resort to telling lies more than their female counterparts (last column). However, there are gender-specific differences within treatments. It seems that the overall gender difference in the second stage is driven by males lying more in MT and $\mathrm{PH}$.

Table 4. Number (proportion) of subjects lying in the second stage.

\begin{tabular}{cccccc}
\hline Treatment & MH & MT & PH & PT & Total \\
\hline Female & $8(0.333)$ & $7(0.333)$ & $7(0.292)$ & $12(0.571)$ & $34(0.378)$ \\
Male & $6(0.273)$ & $20(0.714)$ & $19(0.760)$ & $15(0.517)$ & $60(0.577)$ \\
\hline Total & $14(0.304)$ & $27(0.551)$ & $26(0.531)$ & $27(0.540)$ & $94(0.485)$ \\
\hline
\end{tabular}


To test these, we again ran LR Chi-square tests between genders for each treatment. The tests showed no gender difference for MH and PT ( $p>0.50$ for both). However, it showed a higher proportion of male telling lies in MT $(p=0.007)$ as well as in PH $(p=0.001)$.

Result 3 (between gender). In the second stage, males tell more lies than females only when they could not plan but had an opportunity to tell a lie before, or they could plan but did not have to tell a lie before.

This result is not very straightforward to interpret. First of all, this result shows that males do not necessarily universally tell lies more than their female counterparts when a second opportunity to tell another lie arises. However, when the subjects could not plan but had the opportunity to tell a lie before, then males tell lies more than females. This can be interpreted as relatively more consistent (compensatory) behavior by males (females). Surprisingly, with the possibility to pre-plan, this observation gets reversed, and males tell lies relatively more, when they did not have to tell lies before. These gender differences in moral behavior, and the apparent behavior reversal with the possibility to pre-plan are new observations in the literature as well.

To investigate further, we now focus on pairwise treatment effects for each gender. When the subjects did not have to tell a lie to earn more in the first stage, then only $27.3 \%$ of the myopic males $(\mathrm{MH})$ told a lie in the second stage, but an opportunity to pre-plan (PH) makes $76 \%$ of males tell a lie in the second stage. An LR Chi-square test shows that this difference is significant $(p=0.001)$ as well. Pre-planning does not have such an effect on female subjects $(p=0.755)$. When subjects had an opportunity to tell a lie earlier, and they were myopic (MT) versus they could pre-plan (PT) then the difference was not significant for any gender.

Result 4A (within gender). Pre-planning increases lying behavior only within males in the second stage when they did not have an opportunity to tell a lie in the first stage.

Similar to Result 3, Table 4 also points out gender differences in compensatory moral behavior. When male subjects could plan to tell a lie, but did not have to do so in the first stage, then they were more likely to tell lies in the second stage-showing compensatory behavior. Females did not show such differences. We ran a set of probit and linear probability model (LPM) regressions (the coefficients are reported in Table 5) with the data pair $\mathrm{MH}+\mathrm{PH}$ and $\mathrm{MT}+\mathrm{PT}$. The dependent variable takes the value 1 when the subject lies in the second stage and 0 otherwise. The independent variables are the pre-planning treatment dummy, female dummy, the interaction between the two, and age ('lying in stage $1^{\prime}$ is dropped because of collinearity). The results from both the probit and LPM were the same. For the data MT $+\mathrm{PT}$, the coefficient for female dummy was negative and significant, whereas the interaction between planned and female was positive and significant. For the data $\mathrm{MH}+\mathrm{PH}$, the coefficient for female dummy was not significant, but the interaction between planned and female was positive and significant. These results overall support Result 3 and Result 4A. Moreover, the coefficient for 'age' was negative and significant. These are in line with what the literature (Bucciol et al. [2], Abeler et al. [9], Conrads et al. [13] etc.) has found. Again, we ran further robustness checks through linear probability models (with heteroskedasticity robust standard errors) in which we include planned, Head, and female dummies, and their interactions as independent variables. The regression results (reported in Table A1 in Appendix B) were consistent with the results reported in Table 5 .

Moreover, LR chi-square tests show that for females, there is no significant difference in lying between MH and MT, and suggestive difference in PH and PT ( $p=0.057)$. Whereas for males, there is significant difference in lying between MH and MT ( $p=0.002)$, and only suggestive difference in PH and PT $(p=0.063)$. This is summarized below. 
Table 5. Regression analyses: Lying in the second stage.

\begin{tabular}{|c|c|c|c|c|}
\hline \multirow{2}{*}{ Lying in the Second Stage $=1$. } & \multicolumn{2}{|c|}{ Probit Regression } & \multicolumn{2}{|c|}{ Linear Probability Model } \\
\hline & $\mathbf{M H}+\mathbf{P H}$ & $\mathrm{MT}+\mathrm{PT}$ & $\mathbf{M H}+\mathbf{P H}$ & $\mathrm{MT}+\mathrm{PT}$ \\
\hline Planned $=1$ & $\begin{array}{c}1.384^{* * * *} \\
(0.406)\end{array}$ & $\begin{array}{l}-0.444 \\
(0.349)\end{array}$ & $\begin{array}{c}0.494^{* * *} \\
(0.130)\end{array}$ & $\begin{array}{l}-0.160 \\
(0.129)\end{array}$ \\
\hline Female $=1$ & $\begin{array}{l}-0.117 \\
(0.418)\end{array}$ & $\begin{array}{c}-1.269^{* * *} \\
(0.406)\end{array}$ & $\begin{array}{l}-0.013 \\
(0.139)\end{array}$ & $\begin{array}{c}-0.466^{* * *} \\
((0.134)\end{array}$ \\
\hline Planned $=1 *$ Female $=1$ & $\begin{array}{c}-1.422 * * \\
(0.558)\end{array}$ & $\begin{array}{l}1.259 * * \\
(0.535)\end{array}$ & $\begin{array}{c}-0.507^{* * *} \\
(0.188)\end{array}$ & $\begin{array}{c}0.469^{* *} \\
(0.195)\end{array}$ \\
\hline Age & $\begin{array}{c}-0.124 \text { * } \\
(0.064)\end{array}$ & $\begin{array}{c}-0.125^{* *} \\
(0.057)\end{array}$ & $\begin{array}{c}-0.035^{* *} \\
(0.015)\end{array}$ & $\begin{array}{c}-0.045^{* *} \\
(0.020)\end{array}$ \\
\hline Constant & $\begin{array}{c}2.416 \\
(1.583)\end{array}$ & $\begin{array}{l}3.614^{* *} \\
(1.421)\end{array}$ & $\begin{array}{c}1.118^{* * *} \\
(0.357)\end{array}$ & $\begin{array}{c}1.812 * * * \\
(0.475)\end{array}$ \\
\hline Number of observations & 95 & 99 & 95 & 99 \\
\hline
\end{tabular}

Note. ${ }^{*}, * *$ and ${ }^{* * *}$ denote significance at $10 \%, 5 \%$, and $1 \%$ level. The dependent variable takes the value 1 if the subject lied in the second stage, and 0 otherwise. 'Planned $=1$ ' is a dummy variable that takes value the 1 for $\mathrm{P}$ treatment and 0 for $\mathrm{M}$ treatment; 'Female $=1$ ' is a dummy variable for females. The linear probability models include robust standard errors.

Result 4B (within gender). If pre-planning is not possible, then the opportunity to tell lies in the first stage increases lies in the second stage only for males.

This result is also in line with Result 3, that male subjects follow a more consistent behavior. In case they had the opportunity to tell lies in the first stage, it brings them into a 'slippery slope' and they tell more lies in the second stage. Whereas the existing literature (see, e.g., the review by Mullen and Monin [26]) covers the conditions under which subjects behave consistently instead of a compensatory manner (in moral contexts), it does not point out gender differences. Whereas Results 3, 4A, and 4B hint at such novel gender differences, the current experimental set-up cannot provide any further insights for such differences. Hence, these results call for further investigations in this area of study.

\section{Discussion}

We investigated gender differences in telling lies when the opportunity to tell lies can be repeated, and it may be possible to pre-plan lying behavior. We contribute to the rich literature on the gender differences in lying in two distinct ways. First, to the best of our knowledge, this is the first study in which gender differences in repeated dishonest behavior is documented. Second, this is the first study to investigate gender differences in which dishonest behavior can be pre-planned.

We find overall support to the often-found result in the literature that males tell lies more than females. Adding to the literature, we also find that when pre-planning is not possible, then males tell lies more than females in the first opportunity. However, this difference disappears when pre-planning becomes possible. This is because females tell more lies in the immediate stage if they know that there will be further opportunity to tell lies in the future. After the opportunity to tell a lie is repeated, males tell more lies than females only when they had an opportunity to tell a lie earlier but could not plan for it.

Note that we employ data from an existing experiment, which restricts the scope of the research. For example, when we ran power tests for the required significance of our results, the power for the results were 73.5\% (Result 1), 52.2\% (Result 2), 76.4\% and 91.7\% (Result 3), 92.6\% (Result 4A), and 88.3\% (Result 4B). A pre-registered experiment with continuous measure of lying behavior and larger sample size would allow further robustness checks and replicability of the results with higher power for each of the tests. As discussed in the previous section, the gender difference in telling repeated lies can be interpreted in terms of consistent and compensatory moral behavior. However, whereas the existing literature is very limited in providing a broad idea about such gender differences, the current experimental design cannot provide further insight either. Hence, further investigation in this area is also warranted. 
This study can further be extended in various ways. First, the number of opportunities to tell lies can be increased, and the robustness of these results can be tested. Second, the type of lie can be modified to include socially justified 'white lies.' Erat and Gneezy [27] found that females tell such white lies more than males, but testing it in a repeated setting or in a setting where it can be planned is yet to be investigated. Third, the current structure allows the subjects to make individual decisions. Introducing games in which agents interact with each other repeatedly and can pre-plan their lies would be interesting to observe. Finally, the experiment was run in South Korea, which has its own norms regarding honest behavior. Replicating similar studies in other countries and cultures would be useful.

Supplementary Materials: The date is available online at https:/ / www.mdpi.com/article/10.3390/ g12020044/s1.

Author Contributions: Conceptualization, S.M.C. and J.Y.J.; methodology, J.Y.J.; software, S.-H.K., and C.K. and J.Y.J.; validation, S.M.C.; formal analysis, J.Y.J.; investigation, S.M.C., and J.Y.J.; resources, S.-H.K. and C.K.; data curation, J.Y.J.; writing—original draft preparation, S.M.C.; writing-review and editing, S.M.C., and J.Y.J.; visualization, not applicable.; supervision, not applicable.; project administration, S.M.C., and S.-H.K.; funding acquisition, S.-H.K. and C.K. All authors have read and agreed to the published version of the manuscript.

Funding: This project was supported by a Yonsei University Future-leading Research Initiative (RMS2 2018-22-0088).

Institutional Review Board Statement: The study was conducted according to the guidelines of the Declaration of Helsinki, and approved by the Institutional Review Board of Yonsei University (protocol code 7001988-202005-HR-220-07; date of approval: 21 July 2017).

Informed Consent Statement: Informed consent was obtained from all subjects involved in the study.

Data Availability Statement: The data is uploaded as supplementary material to the manuscript, and is available along with the codes and ReadMe file for replication.

Acknowledgments: The authors thank three anonymous referees for very useful comments.

Conflicts of Interest: The authors declare no conflict of interest.

\section{Appendix A. Instructions}

$<$ Screen $1>$ [For all treatments]

Thank you for participating in our experiment. Please read the instruction carefully. Please wait for further instruction from the experimenter.

$<$ Screen 2> [Only for PH and PT]

You will make two similar decisions in this experiment. In the next page, you will see either "the picture side" or "the number side" of a coin.

[picture side shown] \& [number side shown]

After seeing the side of a coin in the next page, you choose to report either "the picture side appeared" or "the number side appeared."

- If you choose to report that "the picture side appeared," you obtain X.

- If you choose to report that "the number side appeared," you obtain Y.

- The amount of money you obtain depends only on your report.

In your first decision making problem, $\mathrm{X}$ is KRW 5000 and $\mathrm{Y}$ is KRW 0.

In your second decision making problem, X is KRW 2000 and Y is KRW 1000.

In the next page, either "the picture side" or "the number side" of a coin will appear. Please think about what your decision will be.

In your first decision making problem, what would be your report if "the picture side" of a coin appears? What if "the number side" of a coin appears?

In your second decision making problem, what would be your report if "the picture side" of a coin appears? What if "the number side" of a coin appears? 
If you have any question, please raise your hand.

$<$ Screen 3> [For all treatments]

Decision making 1

Your first decision making problem is the following. In the next page, you will see either "the picture side" or "the number side" of a coin.

[picture side shown] \& [number side shown]

After seeing the side of a coin in the next page, you choose to report either "picture side appeared" or "number side appeared."

- If you choose to report "the picture side appeared", you obtain KRW 5000.

1. If you choose to report "the number side appeared", you obtain KRW 0.

2. The amount of money you obtain depends only on your report.

If you have any question, please raise your hand.

$<$ Screen $4>$ [For all treatments]

You choose to report either "picture side appeared" or "number side appeared."

- If you choose to report "the picture side appeared," you obtain KRW 5000.

- If you choose to report "the number side appeared," you obtain KRW 0.

[picture side shown in MH and PH while number side shown in MT and PT]

The

$\odot$ picture side of a coin appeared.

$\odot$ number side

$<$ Screen 5 $>$ [For all treatments]

Decision making 2

Your second decision making problem is the following. In the next page, you will see again either "the picture side" or "the number side" of a coin.

After seeing the side of a coin in the next page, you choose to report either "the picture side appeared" or "the number side appeared."

- If you choose to report "the picture side appeared," you obtain KRW 2000.

- If you choose to report "the number side appeared," you obtain KRW 1000.

- The amount of money you obtain depends only on your report.

If you have any question, please raise your hand.

$<$ Screen 6> [For all treatments]

You choose to report either "the picture side appeared" or "the number side appeared."

- If you choose to report "the picture side appeared," you obtain KRW 2000.

- If you choose to report "the number side appeared," you obtain KRW 1000.

[Number side shown in all treatments]

The

$\odot$ picture side of a coin appeared.

$\odot$ number side

Demographic Survey questions

- When is your birth year?

- What is your gender?

0 Female

1 Male

- What is your college?

0 economics

1 business

2 social science

3 engineering 


\author{
4 statistics \\ 5 life science \\ 6 uic \\ 7 bio system \\ 8 liberal arts \\ 9 natural science \\ 10 dentistry \\ 11 theology \\ 12 education \\ 13 nursing \\ 14 medical \\ - What is your religion? \\ 0 none \\ 1 protestant \\ 2 catholic \\ 3 buddhism \\ 4 other
}

\title{
Appendix B. Further Analyses
}

Table A1. Robustness checks for second stage lying behavior.

\begin{tabular}{|c|c|}
\hline Lying in the Second Stage $=1$. & Linear Probability Model \\
\hline Planned = 1 & $\begin{array}{l}-0.165 \\
(0.128)\end{array}$ \\
\hline Head = 1 & $\begin{array}{l}-0.435^{* * *} \\
(0.134)\end{array}$ \\
\hline Planned $=1 *$ Head $=1$ & $\begin{array}{l}0.659^{* * *} \\
(0.182)\end{array}$ \\
\hline Female $=1$ & $\begin{array}{l}-0.455^{* * *} \\
(0.133)\end{array}$ \\
\hline Planned $=1 *$ Female $=1$ & $\begin{array}{l}0.465^{* *} \\
(0.195)\end{array}$ \\
\hline Head $=1 *$ Female $=1$ & $\begin{array}{l}0.432 * * \\
(0.194)\end{array}$ \\
\hline Planned $=1 *$ Head $=1 *$ Female $=1$ & $\begin{array}{l}-0.968^{* * *} \\
(0.269)\end{array}$ \\
\hline Age & $\begin{array}{l}-0.040^{* * *} \\
(0.012)\end{array}$ \\
\hline Constant & $\begin{array}{l}1.674^{* * *} \\
(0.295)\end{array}$ \\
\hline Number of observations & 194 \\
\hline
\end{tabular}

\section{References}

1. Cartwright, E.; Menezes, M.L. Cheating to win: Dishonesty and the intensity of competition. Econ. Lett. 2014, 122, 55-58. [CrossRef]

2. Bucciol, A.; Landini, F.; Piovesan, M. Unethical behavior in the field: Demographic characteristics and beliefs of the cheater. J. Econ. Behav. Organ. 2013, 93, 248-257. [CrossRef]

3. Fischbacher, U.; Föllmi-Heusi, F. Lies in disguise-an experimental study on cheating. J. Eur. Econ. Assoc. 2013, 11, 525-547. [CrossRef]

4. Azar, O.H.; Yosef, S.; Bar-Eli, M. Do customers return excessive change in a restaurant?: A field experiment on dishonesty. J. Econ. Behav. Organ. 2013, 93, 219-226. [CrossRef] 
5. Garrett, N.; Lazzaro, S.C.; Ariely, D.; Sharot, T. The brain adapts to dishonesty. Nat. Neurosci. 2016, 19, 1727-1732. [CrossRef] [PubMed]

6. Marchewka, A.; Jednorog, K.; Falkiewicz, M.; Szeszkowski, W.; Grabowska, A.; Szatkowska, I. Sex, Lies and fMRI—Gender Differences in Neural Basis of Deception. PLOS ONE 2012, 7, e43076. [CrossRef]

7. Zhang, M.; Liu, T.; Pelowski, M.; Yu, D. Gender difference in spontaneous deception: A hyperscanning study using functional near-infrared spectroscopy. Sci. Rep. 2017, 7, 1-13. [CrossRef]

8. Jacobsen, C.; Fosgaard, T.R.; Pascual-Ezama, D. Why do we lie? a practical guide to the dishonesty literature. J. Econ. Surv. 2018, 32, 357-387. [CrossRef]

9. Abeler, J.; Nosenzo, D.; Raymond, C. Preferences for truth-telling. Econometrica 2019, 87, 1115-1153. [CrossRef]

10. Rosenbaum, S.M.; Billinger, S.; Stieglitz, N. Let's be honest: A review of experimental evidence of honesty and truth-telling. J. Econ. Psychol. 2014, 45, 181-196. [CrossRef]

11. Friesen, L.; Gangadharan, L. Individual level evidence of dishonesty and the gender effect. Econ. Lett. 2012, 117, 624-626. [CrossRef]

12. Ward, D.A.; Beck, W.L. Gender and Dishonesty. J. Soc. Psychol. 1990, 130, 333-339. [CrossRef]

13. Conrads, J.; Irlenbusch, B.; Rilke, R.M.; Walkowitz, G. Lying and team incentives. J. Econ. Psychol. 2013, 34, 1-7. [CrossRef]

14. Muehlheusser, G.; Roider, A.; Wallmeier, N. Gender differences in honesty: Groups versus individuals. Econ. Lett. 2015, 128, 25-29. [CrossRef]

15. Dreber, A.; Johannesson, M. Gender differences in deception. Econ. Lett. 2008, 99, 197-199. [CrossRef]

16. Gylfason, H.F.; Arnardottir, A.A.; Kristinsson, K. More on gender differences in lying. Econ. Lett. 2013, 119, 94-96. [CrossRef]

17. Childs, J. Gender differences in lying. Econ. Lett. 2012, 114, 147-149. [CrossRef]

18. Gino, F.; Krupka, E.L.; Weber, R.A. License to Cheat: Voluntary Regulation and Ethical Behavior. Manag. Sci. 2013, 59, $2187-2203$. [CrossRef]

19. Gino, F.; Pierce, L. Lying to Level the Playing Field: Why People May Dishonestly Help or Hurt Others to Create Equity. J. Bus. Ethic. 2010, 95, 89-103. [CrossRef]

20. Holm, H.J.; Kawagoe, T. Face-to-face lying-An experimental study in Sweden and Japan. J. Econ. Psychol. 2010, 31, 310-321. [CrossRef]

21. Rilke, R.M.; Schurr, A.; Barkan, R.; Shalvi, S. One-by-One or All-at-Once? Self-Reporting Policies and Dishonesty. Front. Psychol. 2016, 7, 113. [CrossRef] [PubMed]

22. Belot, M.; van de Ven, J. How private is private information? The ability to spot deception in an economic game. Exp. Econ. 2019, 20, 19-43. [CrossRef] [PubMed]

23. Chowdhury, S.M.; Kim, C.; Kim, S. Pre-planning and its effects on repeated dishonest behavior: An experiment. Bull. Econ. Res. 2021, 73, 143-153. [CrossRef]

24. Gneezy, U.; Imas, A.; Madarász, K. Conscience accounting: Emotion dynamics and social behavior. Manag. Sci. 2014, 60, 2645-2658. [CrossRef]

25. Fosgaard, T.R.; Hansen, L.G.; Piovesan, M. Separating Will from Grace: An experiment on conformity and awareness in cheating. J. Econ. Behav. Organ. 2013, 93, 279-284. [CrossRef]

26. Mullen, E.; Monin, B. Consistency Versus Licensing Effects of Past Moral Behavior. Annu. Rev. Psychol. 2016, 67, 363-385. [CrossRef] [PubMed]

27. Erat, S.; Gneezy, U. White Lies. Manag. Sci. 2012, 58, 723-733. [CrossRef] 